\title{
Suitability of hydraulic disk brakes for passive actuation of upper-extremity rehabilitation exoskeleton
}

\author{
Arno H.A. Stienen ${ }^{\mathrm{a}, \mathrm{c} *}$, Edsko E.G. Hekman ${ }^{\mathrm{a}}$, Alfred C. Schouten ${ }^{\mathrm{a}, \mathrm{b}}$, Frans C.T. van der Helmª \\ and Herman van der Kooij ${ }^{a, b}$ \\ ${ }^{a}$ Biomechanical Engineering, University of Twente, Enschede, The Netherlands; ${ }^{b}$ Biomechanical Engineering, Delft University of \\ Technology, Delft, The Netherlands; ${ }^{c}$ Physical Therapy and Human Movement Sciences, Northwestern University, Chicago, Illinois, USA
}

(Received 30 September 2008; final version received 10 March 2009)

\begin{abstract}
Passive, energy-dissipating actuators are promising for force-coordination training in stroke rehabilitation, as they are inherently safe and have a high torque-to-weight ratio. The goal of this study is to determine if hydraulic disk brakes are suitable to actuate an upper-extremity exoskeleton, for application in rehabilitation settings. Passive actuation with friction brakes has direct implications for joint control. Braking is always opposite to the movement direction. During standstill, the measured torque is equal to the torque applied by the human. During rotations, it is equal to the brake torque. Actively assisting movement is not possible, nor are energy-requiring virtual environments. The evaluated disk brake has a $20 \mathrm{Nm}$ bandwidth (flat-spectrum, multi-sine) of $10 \mathrm{~Hz}$; sufficient for torques required for conventional therapy and simple, passive virtual environments. The maximum static output torque is $120 \mathrm{Nm}$, sufficient for isometric training of the upper extremity. The minimal impedance is close zero, with only the inertia of the device felt. In conclusion, hydraulic disk brakes are suitable for rehabilitation devices.
\end{abstract}

Keywords: exoskeleton; upper-extremity; disk brakes; rehabilitation; stroke; hydraulics

\section{Introduction}

Patient-friendly robots are used as diagnostic and therapeutic aids in upper-extremities rehabilitation. Through physical manipulation of the arm and assisted by virtual environments, innovative interaction schemes are explored in search of the best possible therapy. Robot-assisted therapy is more intensive and challenging for the patients and less labour intensive for the therapists. It provides the physicians, therapists and the scientific community with more objectively gathered data.

For rehabilitation after stroke, robot-assisted therapy is considered to be as good or better than conventional therapy (Kwakkel et al. 2008; Platz 2003; Prange et al. 2006; van der Lee et al. 2001). These reviews, and the systematic reviews on conventional therapy (Barreca et al. 2003; Feys et al. 2004; Kwakkel et al. 1999; Liu et al. 2006; Schmidt and Lee 1999), indicate that intensive and task-specific exercises consisting of active, repetitive movements, give the best results. Interesting results are also achieved with exercises not directly resembling functional movements. Directly targeting the abnormal muscle-activation couplings over multiple joints (Beer et al. 2004; Brunnstrom 1970) improves the independent joint control and the achievable workspace (Dipietro et al. 2007; Ellis et al. 2005, 2007, 2008). Training in which movements are made against resisting forces to improve muscle strength, potentially a bigger problem than the aforementioned loss of dexterity (Canning et al. 2004; Patten et al. 2004), seem to regain both some quantity and control of muscle force (Ada et al. 2006; Chang et al. 2007; Fasoli et al. 2003; Hortobagyi et al. 2001; Kahn et al. 2006; Rutherford 1988; Stein et al. 2004). The combination of functional exercises with dynamic, high-intensity resistance training looks particulary promising (Patten et al. 2006).

Our self-aligning exoskeleton for the upper extremities, the Dampace (Stienen et al. 2007), should be suitable for the task-specific, repetitive movements with active patient participation. Active participation doesn't necessarily require active, energy-supplying actuators. For movementand force-coordination training, it may be sufficient to apply controlled resistance on the shoulder and elbow joints, as this still allows functional exercises with dynamic, high-intensity resistance. Overall, the selected actuators should be lightweight, powerful and actively controllable.

Controlled resistance can be provided by strictly energydissipating, thus passive, actuators. Passive actuators are potentially lighter and inherently safe, both of which are very important in exoskeletons used in rehabilitation therapy. The disadvantages of passive actuators are that they

*Corresponding author. Email: arnostienen@gmail.com 
can only apply resistance torques against movements, movements cannot be actively assisted (Cai et al. 2006; Colombo et al. 2005; Krebs et al. 2003; Reinkensmeyer et al. 2000; Wolbrecht et al. 2008), virtual environments are restricted to those which do not need external energy and force exercises cannot be done eccentrically. It also requires a separate mechanism supporting the weight of the device and the limb.

Passive actuators can dissipate energy through dampers in conventional pneumatic, hydraulic and electric actuators, resisting respectively the flow of air, fluid or electricity, or through mechanical friction in conventional brakes. A recently developed damper uses electrical currents to control the damping in a magneto-rheological fluid ( $\mathrm{Li}$ and Du 2003; Simmonds 1991; Sims et al. 2004; Spencer et al. 1997; Zhou et al. 2007). These magneto-rheological dampers have been used in prosthetic knees (Herr and Wilkenfeld 2003) and resistance training devices (Dong et al. 2006; Furusho et al. 2005). The resistive forces of all the above dampers are directly dependent on the magnitude of the speed of the actuator, making them difficult to control when combined with the highly variable movement patterns of stroke patients (Dipietro et al. 2009). At almost zero speed and zero reference torque, most dampers will still have a residual friction torque present due to limited valve dimensions, fluid viscosity or magnetic cogging. Mechanical brakes with pure coulomb friction are less dependent on the actuator speed and can be fully disabled, and are therefore chosen in the present design for further exploration.

Mechanical brakes, like hydraulic disk brakes used on mountain bikes, have a high torque-to-weight and torque-tosize ratio, but are untested for use in controlled rehabilitation robots. (Only very recently a similar bicycle disk brake was used in an elbow spasticity simulator, see Grow et al. 2008.) Due to their commercial availability and lightweight and compact designs, hydraulic disk brakes seem appropriate for providing the controlled resistance on the exoskeleton.

The goal of this paper is to determine if hydraulic disk brakes are suitable to mount on an exoskeleton for upper-extremity force-coordination training, by (1) designing an actuation and control system for the disk brakes, (2) analysing the open-loop intrinsic and closed-loop system characteristics of the disk brakes and (3) comparing the power- and torque-to-weight ratios to other passive actuators.

\section{System design}

\subsection{Actuator requirements}

Structured conversations with several physicians, therapists and human movement scientists in the Netherlands resulted in a list of requirements for the exoskeleton and the actuators, including the torques needed for different force- coordination exercises as found in conventional therapy. The controlled disk brakes should be able to deliver $20 \mathrm{Nm}$ of torque with a bandwidth of $5 \mathrm{~Hz}$ to dynamically resist arm movements of stroke patients during therapy (Mirbagheri and Rymer 2008). These requirements should also be sufficient to generate simple virtual environments with which patients can interact. The minimal impedance, the torque felt when moving the arm while no torque is requested, is preferably as low as possible. For these patients, isometricforce measurements and training require static torques up to $100 \mathrm{Nm}$. The disk brake construction should preferably weigh less than $1.0 \mathrm{~kg}$ to be directly mountable on an exoskeleton.

\subsection{Implications of passive actuation}

The use of the passive, energy-dissipating brakes which generate coulomb friction has three functional implications for the control of the joint angles, and therefore for the setup of the system. Firstly, the direction of the braking torque is always opposite to the direction of joint rotation and therefore cannot be manipulated by a control algorithm. Secondly, without movement, the experienced and measured braking torque is equal to the torque applied by the human and not to the potentially desired braking torque. Thirdly, with non-zero joint-rotation speeds the amount of experienced and measured braking torque is equal to the desired braking torque and not to the torque applied by the human. This is captured in the simulation of Figure 1 and the following equations, with $T_{b r \text {,des }}$ the desired and $T_{b r, e x p}$ the experienced braking torque, $T_{\text {hum }}$ the torque applied by the human on the joint, $\dot{\theta}$ the joint speed and sgn the sign-function indicating direction:

$$
T_{b r, \exp }=\left\{\begin{array}{cc}
-T_{h u m} & \text { if } \dot{\theta}=0, \\
-\operatorname{sgn}(\dot{\theta}) T_{b r, d e s} & \text { if } \dot{\theta} \neq 0 .
\end{array}\right.
$$

\subsection{System setup}

The hydraulic disk brake needs to be powered by an active actuator to function. Therefore, a series elastic actuator (SEA) is connected to the hydraulic cylinder in the brake handle (see Figure 2). The amount of joint resistance torque is regulated by controlling the internal hydraulic pressure with the output force of the actuator. A SEA has a better force output resolution than a directly connected electro motor and gearbox, at the cost of bandwidth performance (Pratt and Williamson 1995; Robinson 2000; Veneman et al. 2006; Vallery et al. 2008). With a spring in series, the transferred force is measurable by the spring deflection and suffers less from torque output impurities of the motor due to gearbox friction or motor cogging. The series elastic configuration also makes it possible to use the motor angle in an inner control loop, and not depend on the conditional torque measurement at the joint (Equation 1). Despite the 

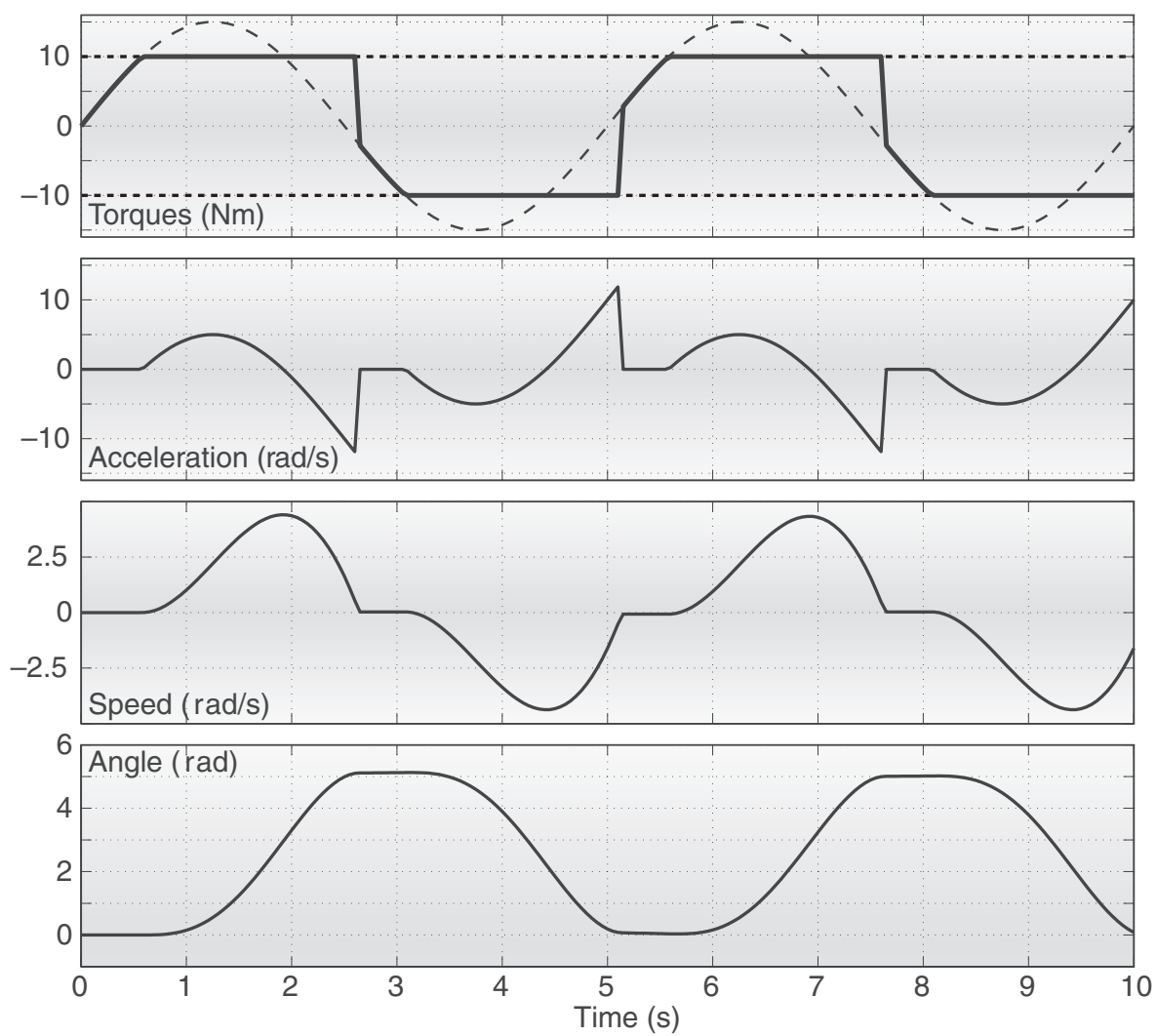

Figure 1. Theoretical effects of passive, energy-dissipating brakes on the control of joint angles. Top figure: The desired absolute braking torque $T_{b r, d e s}$ at $\pm 10 \mathrm{Nm}$ (short-stripped lines) the torque applied by the human on the joint $T_{\text {hum }}$ as a $15 \mathrm{Nm}$ sine (long-stripped lines), and the experienced brake torque $T_{b r \text {,exp }}$ (solid line). Second figure: with unity inertia, this represents both the net-torque applied to the joint and its joint acceleration. The third and fourth figures: Joint angular speed and angle. Note the complex dependency of the experienced brake torque $T_{b r, \exp }$ on the direction of the joint speed and the desired absolute braking torque $T_{b r \text {,des }}$.

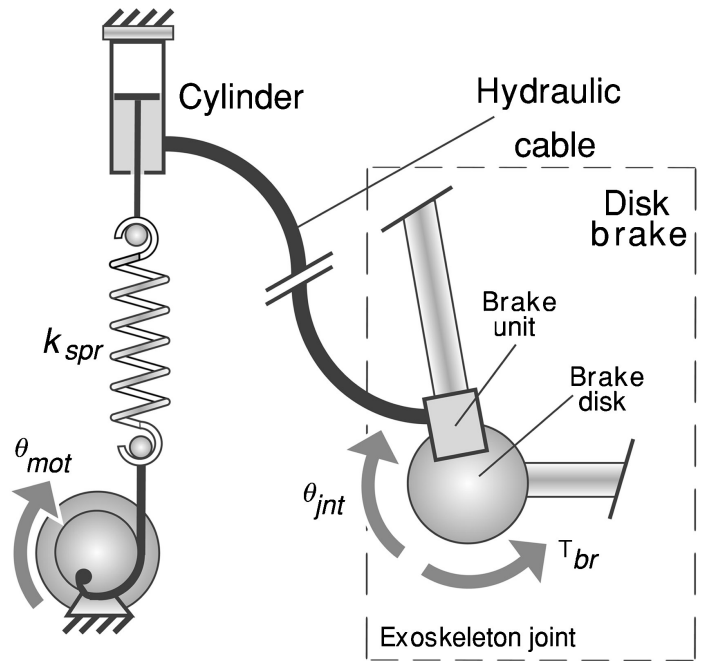

Figure 2. Disk brake as used on the exoskeleton joint, powered by a series elastic actuator (SEA) mounted on the base frame. The rotation of the motor $\theta_{m o t}$ is converted by the spring with stiffness $K_{s p r}$ and the cylinder to a pressure in the hydraulic cable. This pressure is used to control the braking torque $T_{b r}$ on the exoskeleton joint. Note that the braking torque is always in the opposite direction of the joint velocity $\theta_{j n t}$. active actuator, the braking torques in the actuator are still always opposite to the actuator rotation, ensuring passivity at the joint.

It is important to note that as soon as the brake pads in the brake unit engage the brake disk, the cylinder piston in the handle stops moving almost completely due to the high hydraulic stiffness. This simplifies the system analysis, as the spring deflection now only depends on the motor rotation. The lack of cylinder movement adds other reasons to using the elastic element. Without it, force control would depend on the low-fidelity force output of a stationary motor with gearbox (Pratt and Williamson 1995). The limited motor rotations could potentially wear out the internal motor wiring. Using a powerful direct-drive electric motor with a stiff force sensor instead of the SEA is an alternative, but these are far more expensive than SEA configurations.

For the single-axis experimental measurements in this study, the exoskeleton joint was positioned on an axis powered by an external electric motor. This motor generated simulated arm movements or kept the brake disk rotating continuously (see Figure 3)

The electric motor and driver in the SEA are from LTI drives, respectively the LSH050-4-60-320 (nominal 


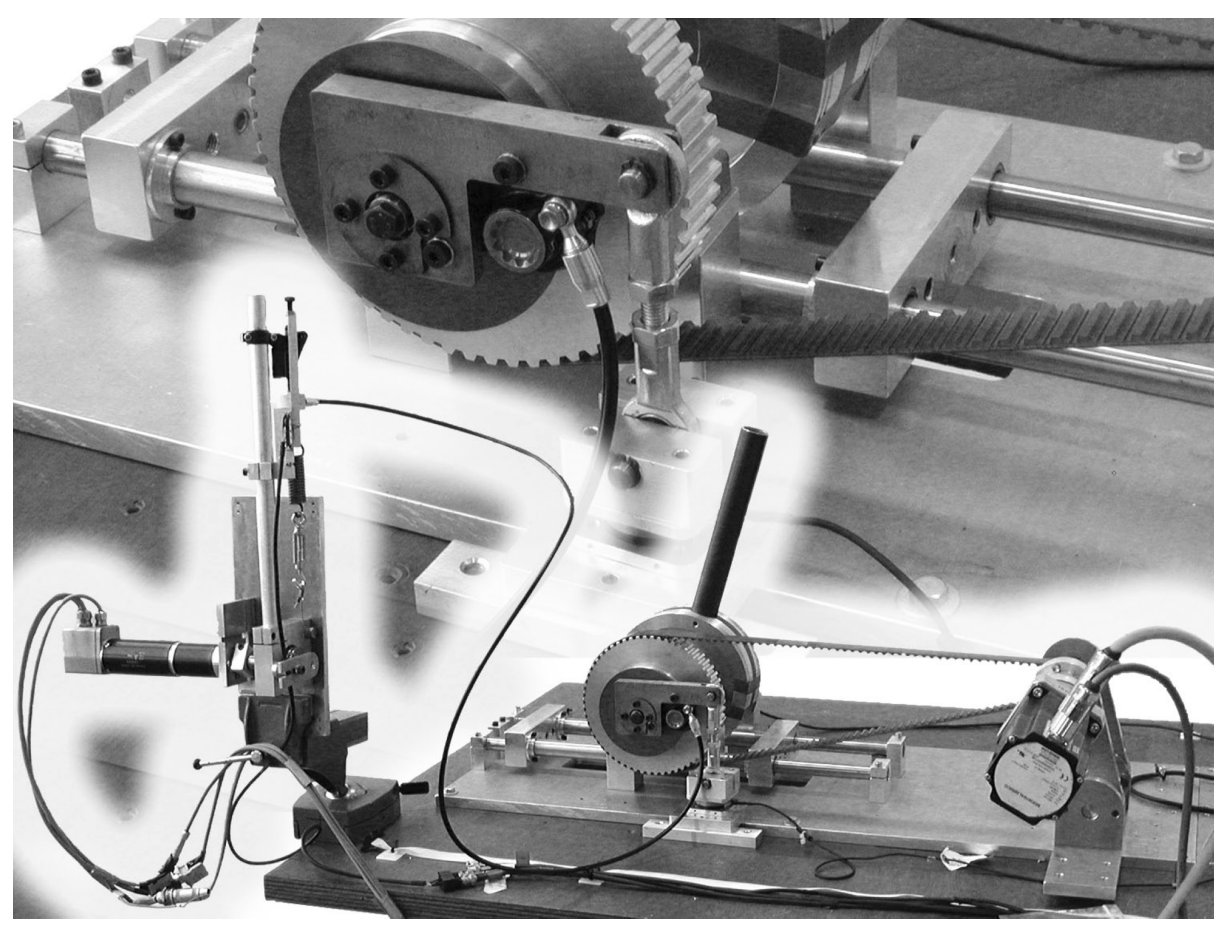

Figure 3. Experimental setup. The brake disk and brake unit are placed on the central axis at the bottom (enlarged as background). The axis is powered by an external electric motor (right) to simulate arm and joint movements. The disk brake is powered by the series elastic actuator (left), with the brake forces measured at a fixed distance from the rotation centre of the axis by a force sensor (middle, beneath brake unit). The spring deflection is measured by the encoder in the brake motor. Note the images does not show the electric motor and force sensor used for the results in this paper, although the setup is exactly the same.

torque: $0.7 \mathrm{Nm}$; maximum speed: $6000 \mathrm{RPM}$ ) and the CDD32.004C (operating voltage: $230 \mathrm{~V}$; maximum current: $7.2 \mathrm{~A}$ ). The motor is combined with a PLE60 gearbox (ratio 1:20) from Neugart. On the externally powered axis (resembling the exoskeleton joint), the hydraulic mono mini disc brake from Hope Technology (weight: $0.45 \mathrm{~kg}$ ), is combined with a L1657 load sensor (capacity: $2224 \mathrm{~N}$ ) from FUTEK Advanced Sensor Technology, mounted at $0.1 \mathrm{~m}$ from the central axis. The disk brake should be able to generate up to $200 \mathrm{Nm}$ of braking torque on a custom steel brake disk (diameter: $0.12 \mathrm{~m}$ ), although due to limited nominal torque of the electric motor in the SEA, it never gets above $120 \mathrm{Nm}$. The load sensor signals are conditioned by a SG-3016 isolated strain gauge input module from ICP DAS. The brake unit generated its brake forces at $0.055 \mathrm{~m}$ from the central axis, on a $0.12 \mathrm{~m}$ diameter brake disk. The rotations of the externally powered axis were measured by a quadrature encoder (resolution: $2500 \mathrm{CPR}$ ) from US Digital, consisting of a transmissive rotary code wheel (outer dimension: 2 inch, inner dimension: 1 inch) and a separate encoder module (EM1).

\subsection{Controller design}

Based on the presumption of a linear relationship between the brake torque $T_{a c t}$ and the motor angle $\theta_{m o t}$ (to be veri- fied in the next sections), the hydraulic disk brake is fully controlled by controlling the SEA (see Figure 4). As the torque measurements depend strongly and non-linearly on the joint speed (see Equation 1), the measured brake torque of the actuator $T_{a c t}$ is not fed back via an outer control loop. A linear inverse model $H_{i n v}$ converts the reference torque $T_{\text {ref }}$ to the reference motor angle $\theta_{\text {ref }}$. All manually identified components outside the inner loop with PID controller are

$$
\begin{aligned}
H_{i n v} & =K_{i n v}=0.0125(\mathrm{rad} / \mathrm{Nm}) \\
H_{f f} & =K_{f f}=0.5(\mathrm{Nm} / \mathrm{rad}) \\
r_{m o t} & =0.025(\mathrm{~m}) \\
K_{s p r} & =15.9 * 10^{3}(\mathrm{~N} / \mathrm{m}) \\
r_{b r} & =0.055(\mathrm{~m}) \\
H_{b r} & =\frac{K_{b r}}{\tau_{b r} s+1} e^{-s \tau_{t}}
\end{aligned}
$$

where the hydraulic disk brake $H_{b r}$ is modeled by a firstorder system with gain $K_{b r}$, time constant $\tau_{b r}$ and transport delay $\tau_{t}$ in the $2 \mathrm{~m}$ hydraulic cables. The above feedforward gain $K_{f f}$ was experimentally determined, but is 


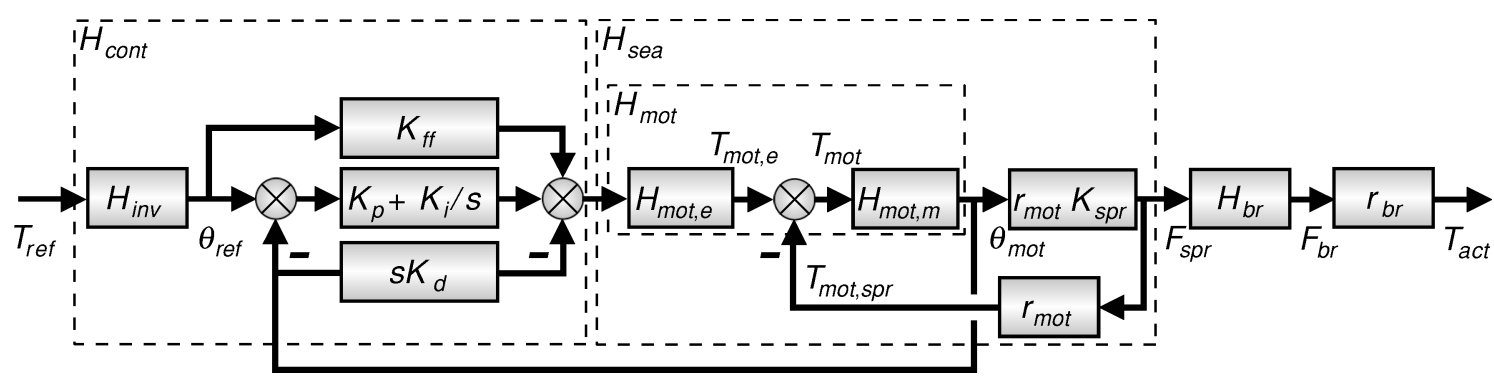

Figure 4. Control diagram of the SEA in combination with the hydraulic disk brake. The reference torque $T_{r e f}$ is converted to a reference motor angle $\theta_{r e f}$ with inverse model $H_{i n v}$. The motor angle is controlled $\left(H_{c o n t}\right)$ with P- and I-actions on the error signal (with gains $K_{p}$ and $K_{i}$ ), and a D-action $K_{d}$ on the measured motor angle. The resulting control signal is fed through the electrical windings of the electric motor $H_{m o t, e}$, which includes the gearing ratio, to get the generated motor torque $T_{m o t, e}$. The second-order model of the mechanical motor $H_{m o t, m}$, including the gearbox inertia, converts the resulting motor torque $T_{m o t}$ to an motor angle displacement $\theta_{m o t}$. The motor angle times the motor radius $r_{m o t}$ and the spring stiffness $K_{s p r}$, gives the springs force $F_{s p r}$, which is the output of the SEA ( $\left.H_{s e a}\right)$. The torque on the motor due to the spring force $T_{m o t, s p r}$ is subtracted from the electrical motor torque $T_{m o t, e}$ to get the resulting motor torque $T_{m o t}$ in the motor model $H_{m o t}$. The controller has a feedforward gain $K_{f f}$ to compensate for this subtraction. The SEA output goes through the hydraulic disk brake $H_{b r}$ to generate the brake force $F_{b r}$ at an distance $r_{b r}$ from the joint axis, resulting in the total brake torque of the actuator $T_{a c t}$.

also roughly equal to the analytical derivation:

$$
K_{f f} \approx \frac{r_{m o t}^{2} K_{s p r}}{i_{g b}}
$$

with the gearbox ratio $i_{g b}$ equal to 20. The theoretical nominal actuator output torque $T_{a c t}$ can be calculated from the nominal motor torque $\bar{T}_{m o t, e}$ (without the gearbox gain):

$$
T_{a c t}=K_{b r} i_{g b} \bar{T}_{m o t, e} \frac{r_{b r}}{r_{m o t}} .
$$

The controllers are programmed in Matlab Simulink (The MathWorks) and compiled to run in an open-source, real-time Linux environment (RTAI) (Barbalace et al. 2008; Bucher and Balemi 2006) with open-source hardware drivers (COMEDI) for the two National Instruments Corporation DAQ devices (analog input and output: PCI-6025, encoder input: PCI-6602) and have real-time logging and graphical user interface possibilities. The controller ran at a minimum of $1000 \mathrm{~Hz}$ on a quad-core computer.

\section{System characteristics}

\subsection{Intrinsic properties}

Before tuning of the SEA controller, the open-loop friction characteristic of the disk brake was analysed. A ramped voltage step applied to the electric motor in the SEA in an open-loop control mode, gave an indication of the relationship between the motor control signal and the output torque $T_{a c t}$. From Figure 5 it is clear that the brake torque has almost no velocity dependency, thus closely resembling coulomb friction with a linear relationship to the normal force. During the constant voltage phases, the brake torque is independent of the angular velocity, closely resembling the normal force relationship seen in pure coulomb friction. The jumps during the voltage ramp phases were accounted for by jumps in the motor angle due to large amount of gearbox friction.

Secondly, possible non-linearities due to stick-slip effects around zero joint speed may affect the performance. To investigate this, the brake disk was brought up to full speed, then to full stop by applying a brake torque step, followed by a slow, ramped release of the brake torque to observe the measured brake torques when disk rotations resumed. At the point of speed resumption in Figure 6, no sudden jumps in the measured brake torque or disk speed can been seen, indicating the absence of stick-slip effects.

\subsection{System identification}

\subsubsection{Method}

For the open- and closed-loop identification, the system was perturbed with multi-sine input signals to estimate the frequency response function $C(s)$ and squared coherence function $\operatorname{Coh}(s)$. These functions are estimated with crossand auto-spectral densities $S(s)$ of input $(i)$ and output $(o)$ (Bendat and Piersol 1986; Jenkins and Watts 1969; van der Helm et al. 2002). For a black-box system with single input and single output, the functions are

$$
\begin{aligned}
C(s) & =\frac{S_{i o}(s)}{S_{i i}(s)}, \\
\operatorname{Coh}(s)^{2} & =\frac{\left|S_{i o}(s)\right|^{2}}{S_{i i}(s) S_{o o}(s)} .
\end{aligned}
$$

The frequency response function $C(s)$ is an estimate for the dynamics of the black-box system, and the squared 

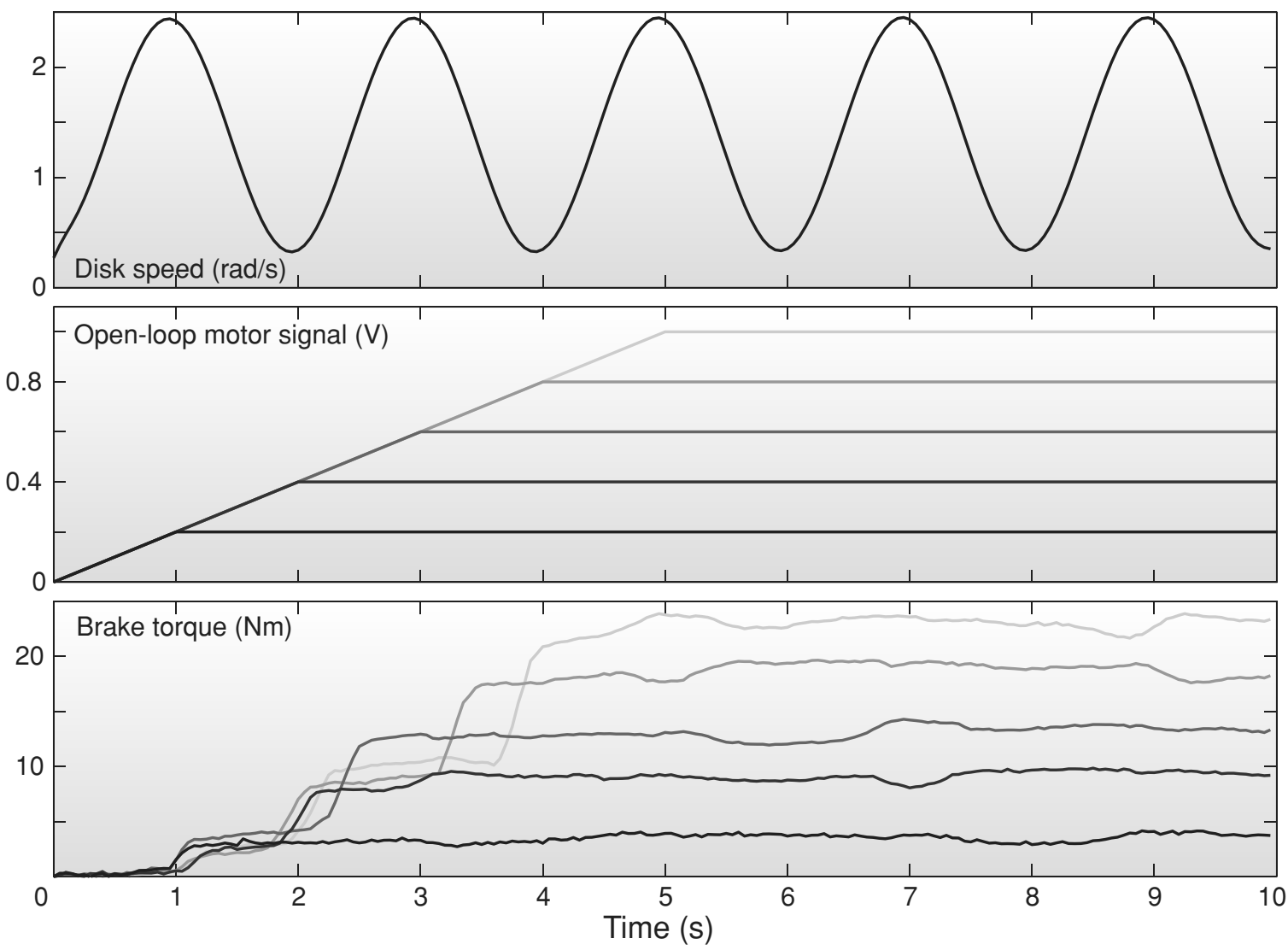

Figure 5. Open-loop intrinsic properties of the hydraulic disk brakes, using an uncontrolled, open-loop actuator. The angular speed of the joint was varied from almost zero to half a rotation per second (top figure), and the SEA powered by an open-loop ramp voltage signal (middle figure). The resulting brake torque is displayed in the bottom figure. The jumps in brake torque during the ramp phase are due to high levels of gearbox friction.

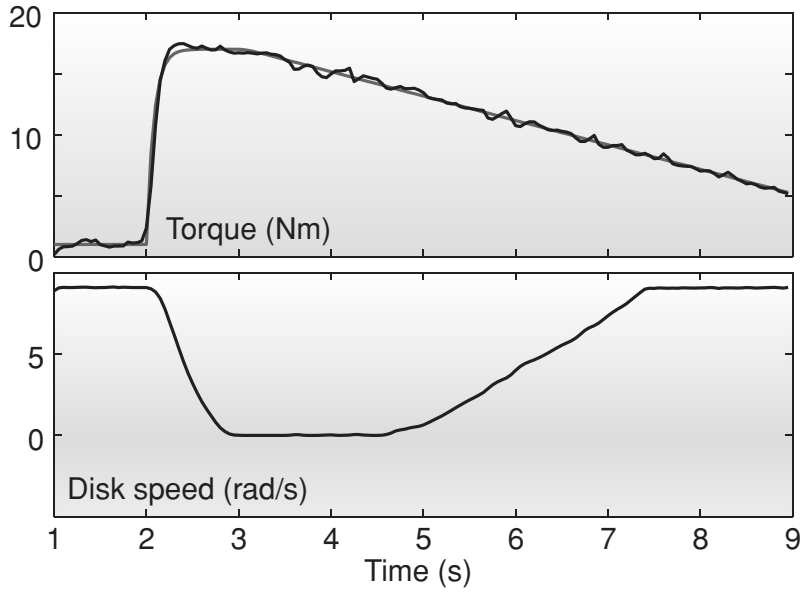

Figure 6. Absence of stick-slip effects during transitions around zero brake disk speed. In the top figure, the desired (grey) and measured (black) brake torques. In the bottom, the angular speed of the externally powered axis to which the brake disk was mounted. coherence function $\operatorname{Coh}(S)$ a measure for the signal to noise ratio at each frequency. The squared coherence (Pintelon and Schoukens 2001) ranges from zero to one, with zero meaning the lack of correlation between the input and output, and one the absence of noise or time-varying behaviour. Higher harmonics in periodic signals may interfere with the interpretation of the coherence function.

The input perturbation signal consisted of 80 summed sines with a observation time of $256 \mathrm{~s}$. The frequencies of the sines were spaced logarithmically from 0.1 to $100 \mathrm{~Hz}$, were of constant power spectral density, and had random phase shifts to reduce amplitude peaks in the summed signal.

The minimum and maximum values of the amplitude of the total signal were scaled relative to three times the standard deviation in both directions. As the sign of the brake torques is directly dependent on the joint rotation direction and cannot be controlled by the actuator, the desired minimum values of the reference signals are always just above zero. The angular disk speed is kept constant at about $1 \mathrm{rad} / \mathrm{s}$. Measurements are repeated four times with 
four uniquely generated multi-sine signals, differing on the random phases. The results are averaged in the frequency domain over four frequencies and the four repetitions to improve the coherence of the measurements and estimates.

The entire actuator system consists of the inner, closedloop motor system followed by the open-loop hydraulic disk brake. These two sub-systems are identified separately, followed by the analysis of the complete system.

\subsubsection{Results}

The frequency response function of the tuned, inner- and closed-loop system of the electric motor $H_{m o t, c l}=\theta_{\text {mot }} / \theta_{\text {ref }}$ (see Figure 4) was identified by it tracking a multi-sine reference motor angle $\theta_{\text {ref }}$. The reference angle had minimum and maximum values of 0.025 and 0.25 ( $\mathrm{rad})$. The response function is plotted in Figure 7 (left), and has a $-3 \mathrm{~dB}$ gain bandwidth of $20 \mathrm{~Hz}$ and a $90^{\circ}$ phase lag bandwidth of $14 \mathrm{~Hz}$.

By using the output from the above closed-loop motor system as input for the open-loop hydraulic disk brake, the frequency response function $H_{b r, o l}=F_{b r} / F_{s p r}$ of the latter was estimated. This response function is based on the forces exerted on the linear cylinder $F_{s p r}$ and by the disk brake $F_{b r}$, not the input motor angle $\theta_{m o t}$ and output actuator torque $T_{a c t}$, to keep the identification as close as possible to the unknown hydraulic disk brake properties. The re- sponse function for $H_{b r, o l}$ is given in Figure 7 (middle). By fitting the hydraulic brake model $H_{b r}$ (Equation 7) on the response functions, parameters $K_{b r}, \tau_{b r}$ and $\tau_{t}$ are found to be $3.9,0.0042 \mathrm{~s}$ and $0.0046 \mathrm{~s}$, respectively. The hydraulic disk brake thus amplifies the force applied on the hydraulic cylinder at the handle almost four times. The time delay $\tau_{b r}$ of the first-order function is of few consequences, but the transport delay $\tau_{t}$ in the $2 \mathrm{~m}$ long tubes causes rapidly increasing phase lag. Note that the experimentally determined $K_{i n v}$ is roughly equal to $1 /\left(r_{m o t} K_{s p r} K_{b r} r_{b r}\right)$, with the value for $K_{b r}$ as found above.

Finally, the frequency response functions of the complete system of closed-loop actuator and open-loop hydraulic disk brake $H_{s y s, c l}=T_{a c t} / T_{r e f}$ were estimated from the reference $T_{r e f}$ and measured output torques $T_{a c t}$. The reference torque $T_{r e f}$ had minimum and maximum values of 2 and $20(\mathrm{Nm})$. The response function is plotted in Figure 7 (right), and has a $-3 \mathrm{~dB}$ gain bandwidth of $18 \mathrm{~Hz}$ and a $90^{\circ}$ phase lag bandwidth of $10 \mathrm{~Hz}$. The major bandwidth limitation in the actuated hydraulic disk brakes is thus the phase lag caused by the length of the hydraulic tubes and the lag of the closed-loop actuator.

The above results show the frequency response functions of the bandwidth measurements. Another direct effect of the used disk brake on the interaction dynamics is the experienced minimal possible impedance. As the brake pads
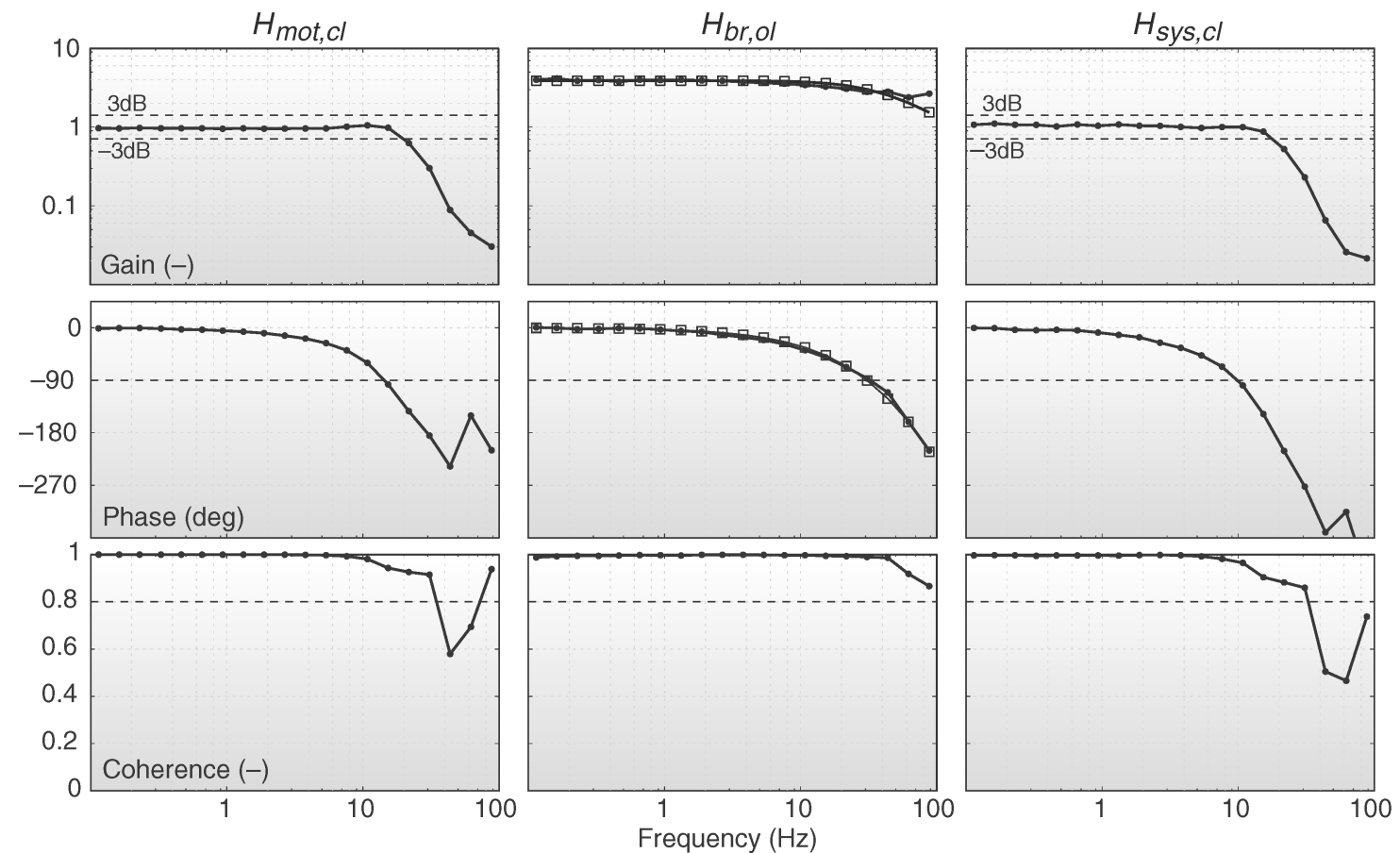

Figure 7. Bode plot of the frequency response functions of the closed-loop system around the electric motor $H_{m o t, c l}=\theta_{\text {mot }} / \theta_{\text {ref }}($ left), the open-loop hydraulic disk brake $H_{b r, o l}=F_{b r} / F_{s p r}$ (middle) and the complete closed-loop system $H_{s y s, c l}=T_{a c t} / T_{r e f}$ (right) for the multi-sine reference torques (black lines with closed dots). The model for the disk brakes $H_{b r}$ (Equation 7 ) was fitted to the open-loop response function $H_{b r, o l}$ (black lines with open squares), giving a good fit. 


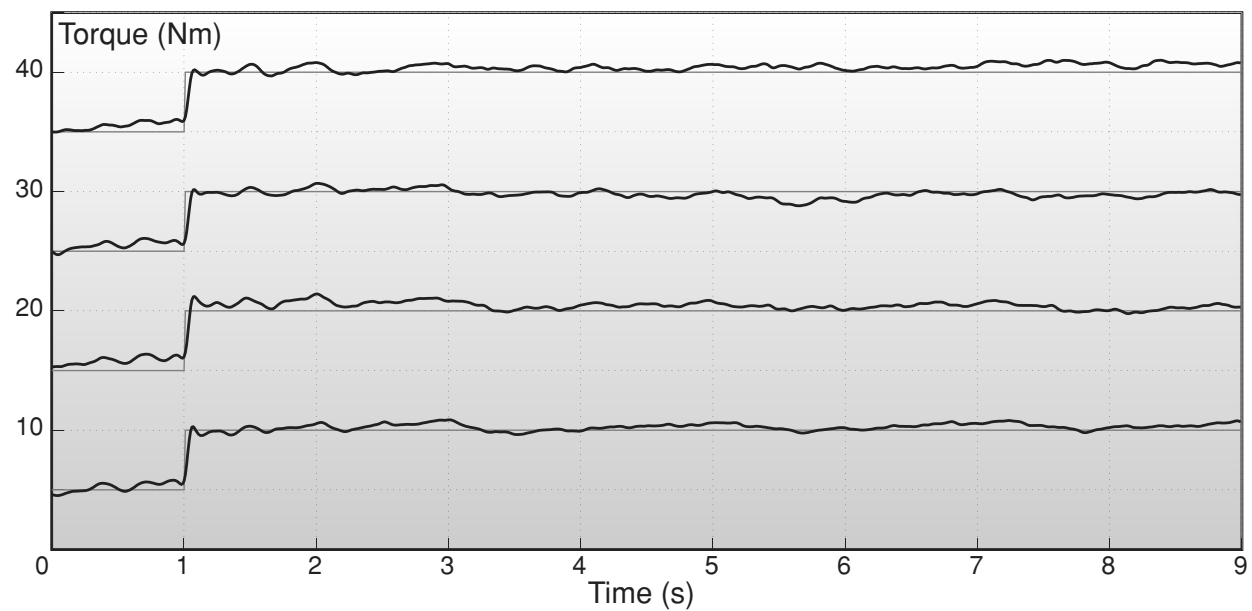

Figure 8. Time plots of step reference signals. In grey, the required torque $T_{r e f}$. In black, the measured torques $T_{a c t}$.

in the brake can fully disconnect from the brake disk, the minimal brake torque is equal to zero for all frequencies, with the only remaining impedance felt due to the acceleration forces of the brake components and the exoskeleton.

\subsection{Control examples}

The performance of the complete closed-loop system of actuator and hydraulic disk brakes is illustrated by two tracking tasks for the actuator torque $T_{\text {act }}$.

The $5 \mathrm{Nm}$ step responses at four different torque levels from $5 \mathrm{Nm}$ to $35 \mathrm{Nm}$ give an illustration of the overshoot and response times of the system. In the step responses of Figure 8, overshoot and response are all acceptable for rehabilitation. Some output variation is seen due to a slight unevenness of the brake disk surface and some heat development in test situation with continued rotations and high torques.

Tracking six sines of different amplitudes, varying in resolution from $5 \mathrm{Nm}$ to $30 \mathrm{Nm}$, give a rough indication of the output resolution. For the sine tracking in Figure 9, the controller has the most problems with the sines with the lowest amplitude, resulting in a torque output resolution of about $1 \mathrm{Nm}$. The present phase lag indicates that the inverse model $H_{i n v}$ is not generating optimal results.

\section{System comparison}

Compared with the pneumatic, hydraulic, electric and magneto-rheological dampers in Table 1 (Huber et al. 1997;
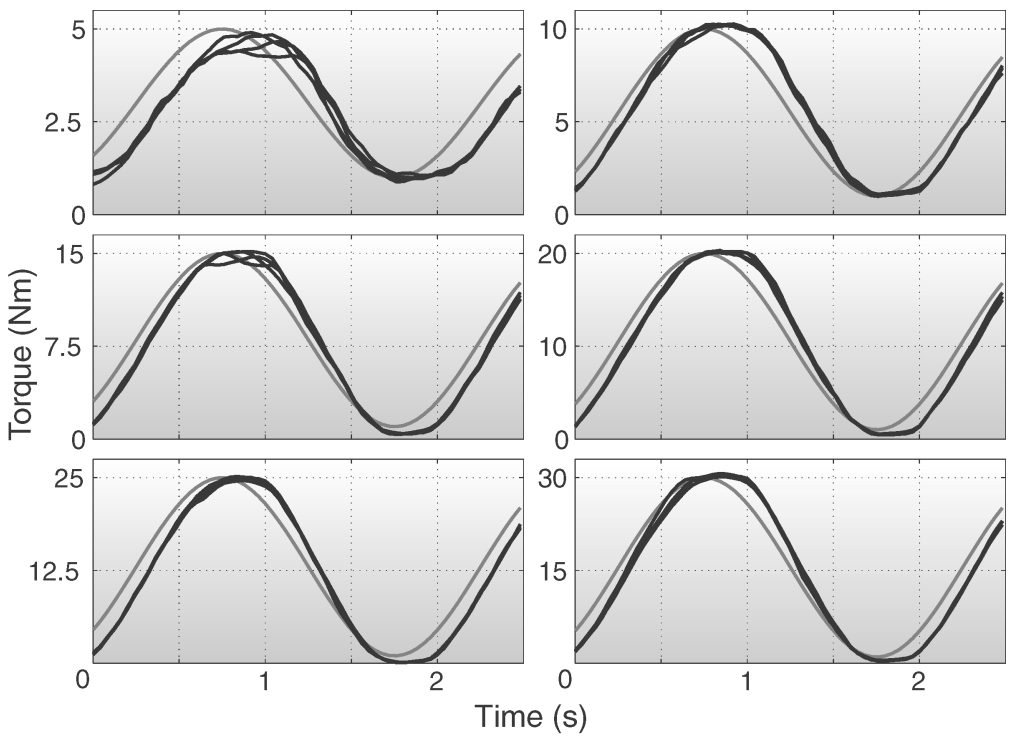

Figure 9. Tracking sine torques of different amplitude. 
Table 1. Power-to-weight and torque-to-weight ratios of passive actuators (approximation).

\begin{tabular}{lcc}
\hline Passive actuator & $\begin{array}{c}\text { Power-to-weight } \\
\text { ratio (W/kg) }\end{array}$ & $\begin{array}{c}\text { Torque-to-weight } \\
\text { ratio }(\mathrm{Nm} / \mathrm{kg})\end{array}$ \\
\hline (Human muscle) & 500 & 160 \\
Pneumatic damper & 2500 & 800 \\
Hydraulic damper & 250000 & 80000 \\
Electric damper & 300 & 100 \\
Magneto-rheological damper & 400 & 130 \\
Mechanical brake & $\infty$ & 400 \\
\hline
\end{tabular}

Zhou et al. 2007), the resistive power-to-weight ratio of the mechanical brake is virtually unlimited due to a constant resistance force and a speed only constrained by heat development. The torque-to-weight ratio of commercially available bicycle disk brake is in the middle of the table, with the torques for the dampers calculated by dividing the power-to-weight ratio by the average peak arm speed of stroke patients $\left(180^{\circ} / \mathrm{s}\right)$ (Mirbagheri and Rymer 2008). Although the torque-to-weight ratio of pneumatic dampers is higher, these dampers are always highly compliant due to the compressibility of air, making them less suitable for applying resistive torques. The hydraulic damper has the highest torque-to-weight ratio, but no damper implementation currently exists with sufficiently high torques and a weight, including valves, below $2 \mathrm{~kg}$. Compared with brakes, dampers always have a minimal amount of friction present and the speed dependency makes their absolute torque levels more difficult to control. Therefore, in our opinion, the mechanical brake is better suited for energy-dissipating force-coordination training than any of the dampers.

\section{Discussion}

A SEA was added to the hydraulic disk brake which was bought in a bicycle store. The SEA is better suited for force actuation than a directly connected electro motor and gearbox, at the cost of some bandwidth performance (Pratt and Williamson 1995; Robinson 2000; Vallery et al. 2008; Veneman et al. 2006). It also made it possible to use the motor angle in an inner control loop, to overcome the particular dynamics of passive actuation with coulomb friction brakes. The SEA actively powers and controls the brake force, but when seen from the patient interaction, the total actuator system is still passive. It can thus only dissipate energy, which makes it inherently safe. Still, the torque bandwidth and output levels make it suitable for functional exercises with dynamic and high-intensity resistance.

The passivity of the disk brakes with coulomb friction has three functional implications for the control of the joint angles. Firstly, the braking torque is always opposite to the direction of joint rotations. Secondly, with zero joint rota- tion speed, the experienced and measured braking torque is equal to the torque applied by the human, and not to the potentially desired braking torque. Thirdly, with nonzero joint rotation speeds, the amount of experienced and measured brake torque, is now equal to the desired braking torque, and not to the torque applied by the human. Passivity also implies that actively assisting movements are impossible and virtual environments are restricted to those which do not need external energy being added to the human arm.

The complete system of closed-loop series elastic actuation and open-loop hydraulic disk brakes has a $20 \mathrm{Nm}$ (flat-spectrum, multi-sine) bandwidth of $10 \mathrm{~Hz}$. The bandwidth is mainly restricted by the transport delays in the $2 \mathrm{~m}$ hydraulic tubes and the lag in the SEA responsiveness, probably due to internal friction in the gearbox. The performance should be sufficient to generate the torques required for force-coordination exercises as used in conventional therapy ( $20 \mathrm{Nm}$ at $5 \mathrm{~Hz}$ ), and for simple virtual environments. When higher bandwidths are required, these can likely be obtained by reducing the length of the hydraulic tubes. Shorter tubes will reduce the transport delays and energy losses due to the elastic properties of the tube wall. Including a higher order inverse model $H_{i n v}$, instead of the linear gain $K_{i n v}$ in Figure 4, or addition of an outer control loop, may further improve the bandwidth of the system.

As the brake pads can be fully disengaged from the brake disk, the minimal impedance - the torque felt when moving the arm while no torque is requested - is close to zero. The minimal torques felt are dominated by the inertia of the brake on the joint. The disk brakes are rated for up to $200 \mathrm{Nm}$, and the electric motor could achieve $120 \mathrm{Nm}$ of this, which is more than enough for isometric training of the upper extremity $(100 \mathrm{Nm})$. At $450 \mathrm{~g}$, the disk brake construction was far below the $1 \mathrm{~kg}$ limit, and suitable to be mounted on an exoskeleton.

During testing, the disk brake occasionally suffered from overheating problems. With the external motor running the joint axis at $\pi \mathrm{rad} / \mathrm{s}$ and while keeping the brake torque at $50 \mathrm{Nm}$, the brake disk would heat up after several minutes. Due to the heat, the brake torque slowly increased. However, heating is not considered a problem in the rehabilitation an exoskeleton, as humans cannot generate enough sustained output power on the brakes during therapeutic exercises.

The other source of brake torque variance was the use of brand new brake disks and brake pads. Each pair of pads needs a couple of minutes of constant wear and tear to get the optimal surface smoothness and constant braking torque. In the test setup, continual wear and tear eventually affected system performance. But in a rehabilitation exoskeleton, wear and tear are minimal. The life span of a pair of pads is expected to be on the scale of years. Replacement of the inexpensive pads is straightforward. 


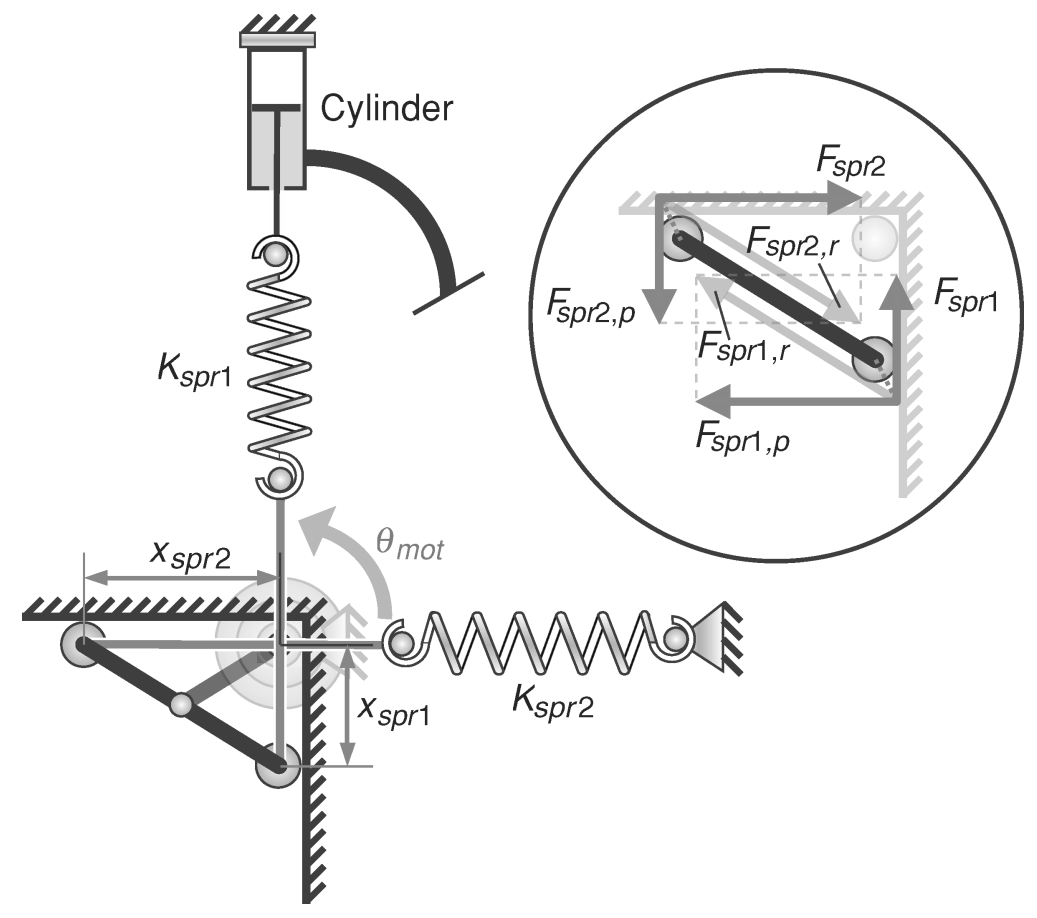

Figure 10. Modified SEA setup in a zero-energy configuration with second spring, reducing motor requirements. The runner-on-rails mechanism (lower left) is statically balanced for any motor angle $\theta_{\text {mot }} . K$ is the spring stiffness, $x$ the spring deflection and $F$ the spring force, with $s p r 1$ and ${ }_{s p r 2}$ indicating spring 1 (directly connected to the hydraulic cylinder) and spring 2 (compensation spring). Inset: The spring forces with decomposition along the runner $_{, r}$ and perpendicular,$p$. The forces are shown with a slight offset to improve readabilty.

\subsection{Zero energy implementation}

In the SEA setup of Figure 2, the electric motor must apply constant power to keep the spring deflected during static brake torque generation. The output brake force is roughly four times the applied force at the handle, with the total relationship between the nominal motor torque and the output brake torque according to Equation 9. Thus, to get a constant brake torque $T_{b r}$ of $20 \mathrm{Nm}$ and $100 \mathrm{Nm}$, the nominal output torque of the motor $T_{m o t, e}$ should be respectively $0.12 \mathrm{Nm}$ and $0.58 \mathrm{Nm}$. (The electric motor was with $0.7 \mathrm{Nm}$ overpowered for the static tasks.)

To reduce the static loads on the electric motor, a statically balanced mechanism can be used with two idealsprings. This reduces the function of the electric motor to generating change of equilibrium positions, making the use of smaller and cheaper electric motors possible.

Adding a second spring can reduce the torque requirement on the motor by counteracting the deflection (see Figure 10). With both springs and ideal-springs, the mechanism is always in static equilibrium, only requiring motor torques to accelerate and decelerate the mechanism. (Theoretically, ideal-springs deflect linearly with increasing force and have zero spring length at zero applied force.) This mechanism can be used, as the hydraulic cylinder in the handle has almost no further displacement when the brake pads are engaging the brake disk. Therefore, the connection between the spring and the hydraulic cylinder can be seen as a connection to the fixed world, maintaining ideal-spring properties in the statically balanced mechanism.

\subsection{Conclusion}

In conclusion, hydraulic disk brakes are suitable to actuate an upper-extremity exoskeleton for forces coordination training in stroke rehabilitation. The analysis of the openloop intrinsic properties and closed-loop system performance of the disk brakes showed the brakes to be suitable for dynamic, high-intensity resistance exercises. Compared to other passive actuators, the hydraulic disk brakes have a descent power- and torque-to-weight ratio. Commercial designs are easily available from bicycle stores for the performance required for rehabilitation.

The hydraulic disk brakes were found to comply with the stated requirements, four of these disk brakes were mounted on the Dampace exoskeleton (Stienen et al. 2007). These disk brakes are powered by the original series elastic actuators, not the zero-energy implementation.

\section{Acknowledgements}

This work was supported by SenterNovem, the Netherlands, grant TSGE2050. The authors would like to thank Gert-Jan Nevenzel 
for his assistance in design, construction and maintenance of the experimental setup.

\section{References}

Ada L, Dorsch S, Canning C. 2006. Strengthening interventions increase strength and improve activity after stroke: a systematic review. Aust J Physiother. 52(4):241-248.

Barbalace A, Luchetta A, Manduchi G, Moro M, Soppelsa A, Taliercio C. 2008. Performance comparison of VxWorks, Linux, RTAI, and Xenomai in a hard real-time application. IEEE Trans Nucl Sci. 55(1):435-439.

Barreca S, Wolf S, Fasoli S, Bohannon R. 2003. Treatment interventions for the paretic upper limb of stroke survivors: a critical review. Neurorehabil Neural Repair. 17(4):220-226.

Beer R, Dewald J, Dawson M, Rymer W. 2004. Target-dependent differences between free and constrained arm movements in chronic hemiparesis. Exp Brain Res. 156(4):458-470.

Bendat J, Piersol A. 1986. Random data: analysis and measurement procedures. New York: Wiley.

Brunnstrom S. 1970. Movement therapy in hemiplegia: a neurophysiological approach. New York: Harper and Row.

Bucher R, Balemi S. 2006. Rapid controller prototyping with Matlab/Simulink and Linux. Control Eng Pract. 14(2):185192.

Cai L, Fong A, Otoshi C, Liang Y, Burdick J, Roy R, Edgerton V. 2006. Implications of assist-as-needed robotic step training after a complete spinal cord injury on intrinsic strategies of motor learning. J Neurosci. 26(41):10564-10568.

Canning C, Ada L, Adams R, O'Dwyer N. 2004. Loss of strength contributes more to physical disability after stroke than loss of dexterity. Clin Rehabil. 18(3):300-308.

Chang J, Tung W, Wu W, Huang M, Su F. 2007. Effects of robotaided bilateral force-induced isokinetic arm training combined with conventional rehabilitation on arm motor function in patients with chronic stroke. Arch Phys Med Rehabil. 88(10):1332-1338.

Colombo R, Pisano F, Micera S, Mazzone A, Delconte C, Carrozza M, Dario P, Minuco G. 2005. Robotic techniques for upper limb evaluation and rehabilitation of stroke patients. IEEE Trans Neural Syst Rehabil Eng. 13(3):311-324.

Dipietro L, Krebs H, Fasoli S, Volpe B, Hogan N. 2009. Submovement changes characterize generalization of motor recovery after stroke. Cortex. 45(3):318-324.

Dipietro L, Krebs H, Fasoli S, Volpe B, Stein J, Bever C, Hogan N. 2007. Changing motor synergies in chronic stroke. J Neurophysiol. 98(2):757-768.

Dong S, Lu K, Sun J, Rudolph K. 2006. A prototype rehabilitation device with variable resistance and joint motion control. Med Eng Phys. 28(4):348-355.

Ellis M, Holubar B, Acosta A, Beer R, Dewald J. 2005. Modifiability of abnormal isometric elbow and shoulder joint torque coupling after stroke. Muscle Nerve. 32(2):170-178.

Ellis M, Sukal T, DeMott T, Dewald J. 2007. ACT-3D exercise targets gravity-induced discoordination and improves reaching work area in individuals with stroke. Proceedings of the 10th ICORR, 2007. Noordwijk, The Netherlands.

Ellis M, Sukal T, DeMott T, Dewald J. 2008. Augmenting clinical evaluation of hemiparetic arm movement with a laboratorybased quantitative measurement of kinematics as a function of limb loading. Neurorehabil Neural Repair. 22(4):321-329.

Fasoli S, Krebs H, Stein J, Frontera W, Hogan N. 2003. Effects of robotic therapy on motor impairment and recovery in chronic stroke. Arch Phys Med. Rehab. 84(4):477-482.

Feys H, De Weerdt W, Verbeke G, Steck G, Capiau C, Kiekens C, Dejaeger E, Van Hoydonck G, Vermeersch G, Cras P. 2004. Early and repetitive stimulation of the arm can substantially improve the long-term outcome after stroke: a 5-year followup study of a randomized trial. Stroke. 35(4):924-929.

Furusho J, Koyanagi K, Nakanishi K, Fujii Y, Domen K, Miyakoshi K, Ryu U, Takenaka S, Inoue A. 2005. A 3-D exercise machine for upper-limb rehabilitation using ER actuators with high safety. In: Proceedings of 11th AIM, 2005. Jul 24-28. Monterey (CA), p. 455-460.

Grow D, Wu M, Locastro M, Arora S, Bastian A, Okamura A. 2008. Haptic simulation of elbow joint spasticity. In: Proceedings of 16th HAPTICS, 2008. Mar 13-14. Reno (NV). p. 475476.

Herr H, Wilkenfeld A. 2003. User-adaptive control of a magnetorheological prosthetic knee. Ind Robot. 30(1):42-55.

Hortobagyi T, Tunnel D, Moody J, Beam S, DeVita P. 2001. Lowor high-intensity strength training partially restores impaired quadriceps force accuracy and steadiness in aged adults. $\mathrm{J}$ Gerontol A Biol Sci Med Sci. 56(1):B38-B47.

Huber J, Fleck N, Ashby M. 1997. The selection of mechanical actuators based on performance indices. Proc R Soc A. 453(1965):2185-2205.

Jenkins G, Watts D. 1969. Spectral analysis and its applications. San Francisco (CA): Holden-Day.

Kahn L, Lum P, Rymer W, Reinkensmeyer D. 2006. Robot-assisted movement training for the stroke-impaired arm: Does it matter what the robot does? J Rehabil Res Dev. 43(5):619-630.

Krebs H, Palazzolo J, Dipietro L, Volpe B, Hogan N. 2003. Rehabilitation robotics: Performance-based progressive robotassisted therapy. Auton Robot. 15(1):7-20.

Kwakkel G, Kollen B, Krebs H. 2008. Effects of robot-assisted therapy on upper limb recovery after stroke: a systematic review. Neurorehabil Neural Repair. 22(2):111-121.

Kwakkel G, Wagenaar R, Twisk J, Lankhorst G, Koetsier J. 1999. Intensity of leg and arm training after primary middle-cerebralartery stroke: a randomised trial. Lancet. 354(9174):191-196.

Li W, Du H. 2003. Springer; design and experimental evaluation of a magnetorheological brake. Int J Adv Manuf Technol. 21(7):508-515

Liu J, Cramer S, Reinkensmeyer D. 2006. Learning to perform a new movement with robotic assistance: comparison of haptic guidance and visual demonstration. J Neuroengineering Rehabil. $3: 20$

Mirbagheri M, Rymer W. 2008. Time-course of changes in arm impairment after stroke: variables predicting motor recovery over 12 months. Arch Phys Med Rehabil. 89(8):1507-1513.

Patten C, Dozono J, Schmidt S, Jue M, Lum P. 2006. Combined functional task practice and dynamic high intensity resistance training promotes recovery of upper-extremity motor function in post-stroke hemiparesis: a case study. J Neurol Phys Ther. 30(3):99-115.

Patten C, Lexell J, Brown H. 2004. Weakness and strength training in persons with poststroke hemiplegia: Rationale, method, and efficacy. J Rehabil Res. Dev. 41(3A):293-312.

Pintelon R, Schoukens J. 2001. System identification: a frequency domain approach. New York: IEEE Press.

Platz T. 2003. Evidence-based arm rehabilitation - a systematic review of the literature. Nervenartz. 74(10):841-849.

Prange G, Jannink M, Groothuis-Oudshoorn C, Hermens H, IJzerman M. 2006. Systematic review of the effect of robot-aided therapy on recovery of the hemiparetic arm after stroke. J Rehabil Res Dev. 43(2):171-184.

Pratt G, Williamson M. 1995. Series elastic actuators. In: Proceedings of IROS, 1995. Aug 5-9. p. 399-406.

Reinkensmeyer D, Kahn L, Averbuch M, McKenna-Cole A, Schmit B, Rymer W. 2000. Understanding and treating arm movement impairment after chronic brain injury: progress with the ARM guide. J Rehabil Res Dev. 37(6):653-662. 
Robinson D. 2000. Design and analysis of series elasticity in closed-loop actuator force control. Cambridge (MA): MIT.

Rutherford O. 1988. Muscular coordination and strength training. Implications for injury rehabilitation. Sports Med. 5(3):196202.

Schmidt R, Lee T. 1999. Motor control and learning. 3rd ed. Champaign (IL): Human Kinetics.

Simmonds A. 1991. Electro-rheological valves in a hydraulic circuit. IEE Proc D Control Theory Appl. 138(4):400-404.

Sims N, Holmes N, Stanway R. 2004. A unified modelling and model updating procedure for electrorheological and magnetorheological vibration dampers. Smart Mater Struct. 13(1):100-121.

Spencer B, Dyke S, Sain M, Carlson J. 1997. Phenomenological model for magnetorheological dampers. J Eng Mech-ASCE. 123(3):230-238.

Stein J, Krebs H, Frontera W, Fasoli S, Hughes R, Hogan N. 2004. Comparison of two techniques of robot-aided upper limb exercise training after stroke. Am J Phys Med Rehabil. 83(9):720728.

Stienen A, Hekman E, van der Helm F, Prange G, Jannink M, Aalsma A, van der Kooij H. 2007. Dampace: dynamic forcecoordination trainer for the upper extremities. Proceedings of the 10th ICORR, 2007. Noordwijk, The Netherlands.
Vallery H, Veneman J, van Asseldonk E, Ekkelenkamp R, M Buss van der Kooij H. 2008. Compliant actuation of rehabilitation robots: benefits and limitations of series elastic actuators. IEEE Rob Autom Mag. 15(3):60-69.

van der Helm F, Schouten A, de Vlugt E, Brouwn G. 2002. Identification of intrinsic and reflexive components of human arm dynamics during postural control. J Neurosci Methods 119(1):114.

van der Lee J, Snels I, Beckerman H, Lankhorst G, Wagenaar R, Bouter L. 2001. Exercise therapy for arm function in stroke patients: a systematic review of randomized controlled trials. Clin Rehabil. 15(1):20-31.

Veneman J, Ekkelenkamp R, Kruidhof R, van der Helm F, van der Kooij H. 2006. A series elastic- and Bowdencable-based actuation system for use as torque actuator in exoskeleton-type robots. Int J Robot Res. 25(3):261281.

Wolbrecht E, Chan V, Reinkensmeyer D, Bobrow J. 2008. Optimizing compliant, model-based robotic assistance to promote neurorehabilitation. IEEE Trans Neural Syst Rehabil Eng. 16(3):286-297.

Zhou W, Chew C, Hong G. 2007. Cambridge Univ Press; development of a compact double-disk magneto-rheological fluid brake. Robotica. 25(04):493-500. 

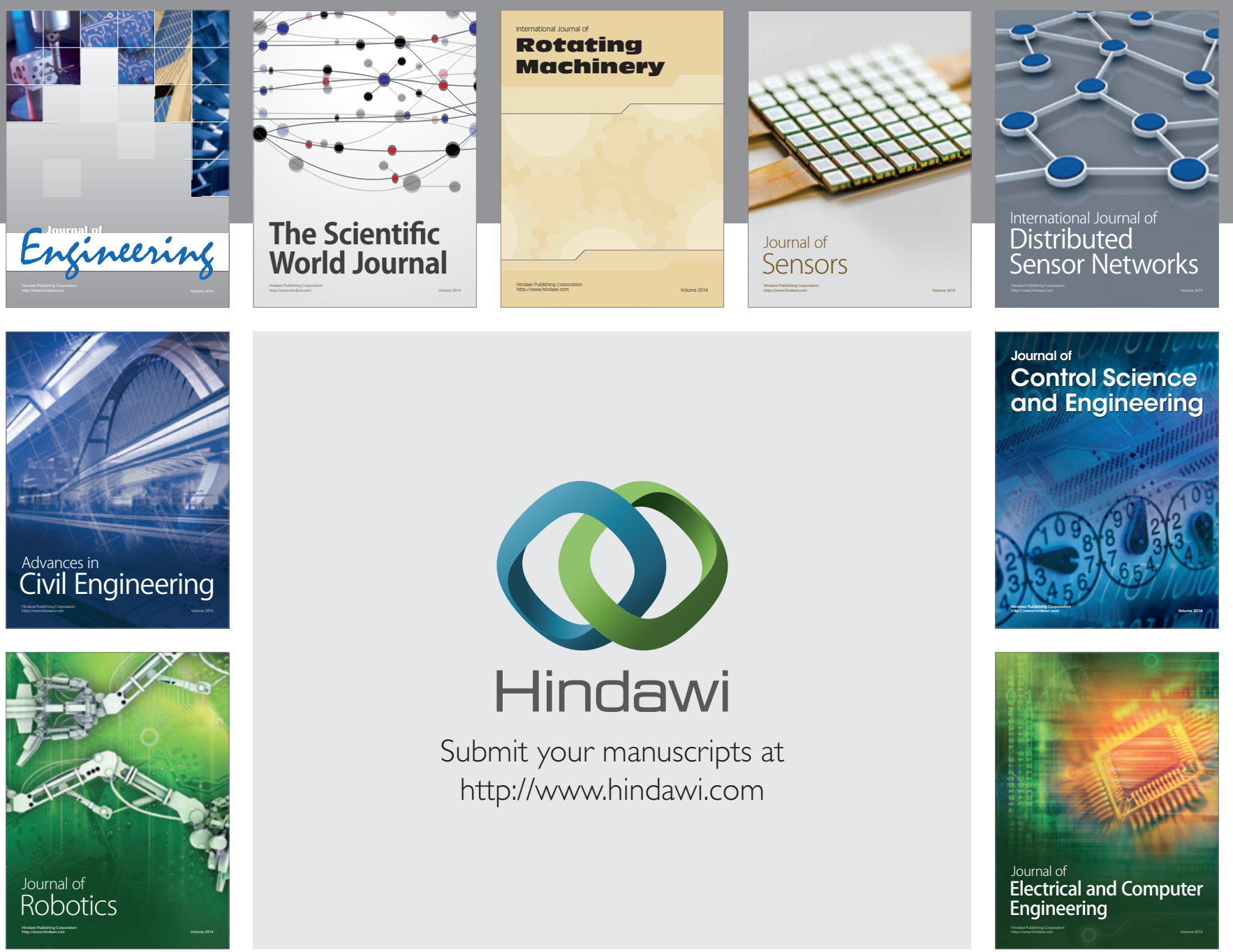

Submit your manuscripts at

http://www.hindawi.com
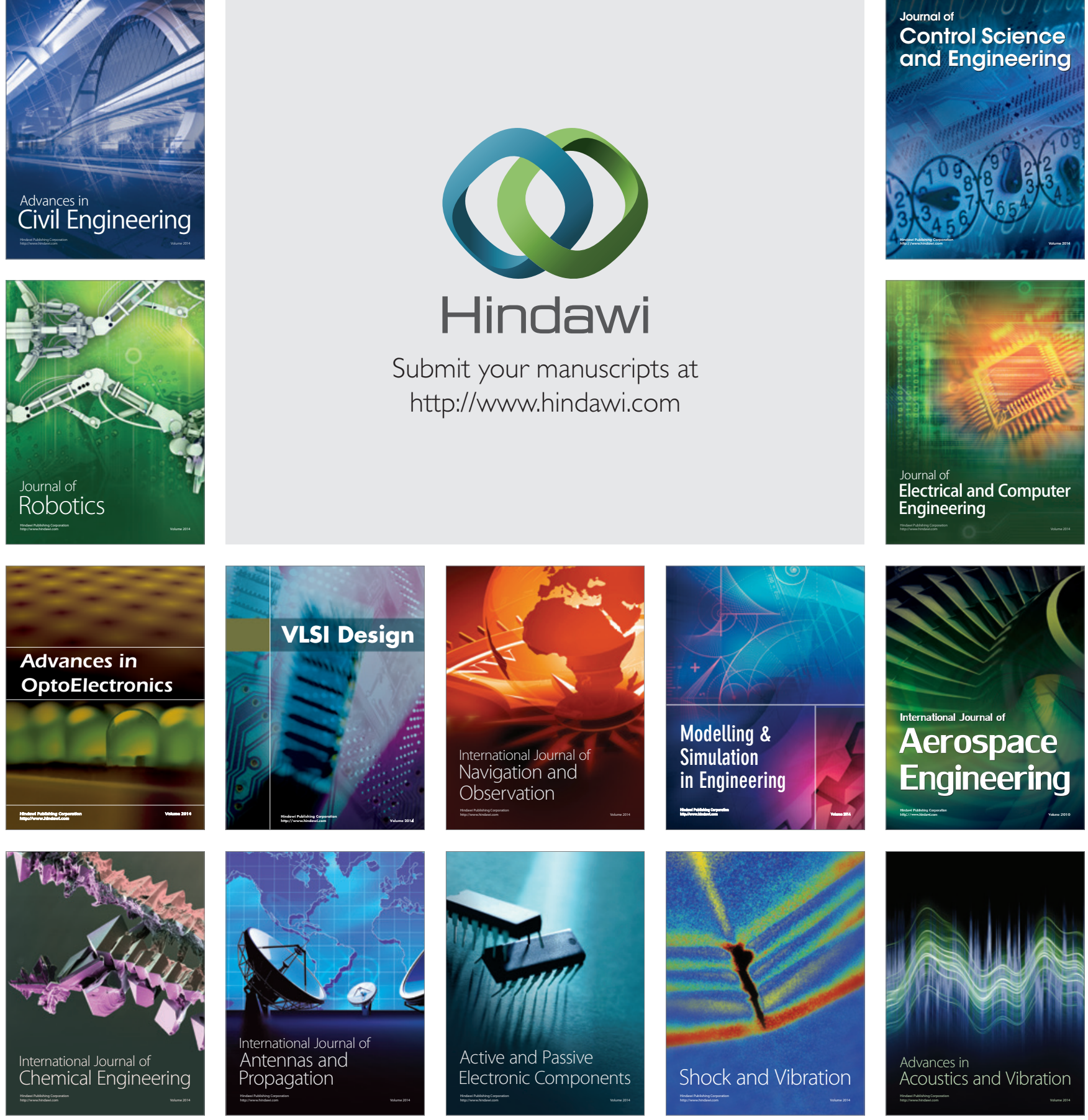